\title{
Cuba após a Guerra Fria: mudanças econômicas, nova agenda diplomática e o limitado diálogo com os EUA
}

Cuba after the Cold War: economic change, new diplomatic agenda and the limited dialogue with the United States

MAURÍCIO SANTORO*

Rev. Bras. Polít. Int. 53 (1): 130-140 [2010]

Introdução

Este texto analisa as transformações econômicas em Cuba após a Guerra Fria. O fim da URSS forçou o país a uma radical reorientação de sua economia, buscando novas formas de inserção no mercado internacional - basicamente, o incentivo ao turismo e à iniciativa privada estrangeira para compensar a perda dos subsídios soviéticos. Contudo, as reformas não se traduziram em abertura política. A transmissão de poder de Fidel para Raúl Castro representa inclusive o retrocesso na limitada liberalização nesse campo.

Em seguida, o artigo examina a reorientação da agenda diplomática cubana durante o mesmo período, com o aprofundamento dos vínculos com União Européia, China, Canadá e os países da América Latina. Apesar dos problemas que persistem para a economia de Cuba e para a qualidade de vida de sua população, a conclusão das duas seções é que o governo da ilha foi bem-sucedido em evitar o colapso do regime socialista e em articular uma nova rede de aliados internacionais, que lhe dá algum espaço de manobra para as complexas negociações com os Estados Unidos.

Por fim, o artigo examina as perspectivas do diálogo entre Havana e Washington na presidência de Barack Obama, com ceticismo quanto a avanços significativos nos temas mais controversos, como o embargo econômico, mas otimista no que diz respeito a acordos pontuais em questóes de menor impacto, que podem pavimentar o caminho rumo a entendimentos mais ambiciosos. Estas transformações são baseadas na comunidade cubano-americana, que passa por mudanças geracionais, com a gradual substituição dos antigos líderes, que

* Professor de Relações Internacionais da Fundação Getúlio Vargas do Rio de Janeiro - FGV-RJ (mauriciosantoro1978@gmail.com). 
viveram o trauma da Revolução de 1959 e do exílio, pela nova leva de jovens dirigentes, mais pragmáticos diante da possibilidade de acordos com o governo de Cuba. É fundamental compreender o papel desses novos atores para entender as possibilidades das negociações diplomáticas.

\section{As mudanças econômicas durante o período especial}

O termo "Período Especial em Tempos de Paz" é a expressão usada pelo governo cubano para definir a época entre 1990 e 2005, quando a economia da ilha passou pelo choque mais brutal desde a Revolução. O ingresso de Cuba no bloco soviético havia consolidado uma relação político-econômica na qual a ilha exportava produtos primários (sobretudo açúcar e tabaco) a preços vantajosos aos países sob a égide da URSS, e importava produtos industrializados e combustível a valores abaixo do mercado internacional.

Esses arranjos chegaram ao fim junto com a União Soviética e seus regimessatélites, entre 1989 e1991. Os impactos sobre Cuba foram brutais. Entre 1990 e 1994, o PIB cubano caiu 36\%; as exportações, 80\%; e as importações, $73 \%$. (Pérez-López, 2008: 170; Domingues, 2008). A situação que as estatísticas refletem foi a da perda do poder de compra cubano no mercado internacional, com a consequente escassez de gêneros básicos, como alimentos e combustível, e a adoção de rígidos programas de austeridade e racionamento, originalmente elaborados para ser implementados no caso de guerra.

$\mathrm{O}$ déficit na balança comercial tem sido um problema crônico desde a Revolução, mas os subsídios soviéticos haviam amenizado a situação. Sem poder contar novamente com o auxílio da URSS, o governo lançou uma série de reformas econômicas para lidar com a crise. As medidas foram centradas na abertura à iniciativa privada e a reforma mais expressiva foi a permissão para que empresas estrangeiras se instalassem em Cuba. Contudo, o governo examinou as experiências internacionais e rejeitou a via das "terapias de choque" adotadas na Rússia e na Europa Oriental. A estratégia cubana é gradualista, com forte condução por parte do Estado e se parece mais às políticas implementadas na China e no Vietnã. Por exemplo, os investimentos externos precisam ser feito por meio de joint-ventures, na qual o Estado assume $50 \%$ do controle de cada negócio.

A maior transformação ocorreu no setor de turismo, que se tornou a principal atividade econômica de Cuba, desbancando a produção de açúcar. As grandes cadeias hoteleiras européias, em particular as espanholas, afluíram para a ilha. A expansão do turismo gerou igualmente um amplo mercado de trabalho em tempo integral ou parcial para muitos cubanos, em atividades informais como guias, motoristas e garçons. Do ponto de vista social, o acesso a moedas fortes dólares ou euros - tornou os prestadores de serviços aos estrangeiros um grupo privilegiado na sociedade cubana, minando alguns dos valores de igualitarismo e austeridade da Revoluçãa. $\mathrm{O}$ aspecto mais problemático é o retorno da prostituição 
e do turismo sexual em larga escala, cuja erradicação havia sido um dos orgulhos do regime estabelecido em 1959.

As reformas foram bem-sucedidas nos campos do petróleo e da mineração, cuja produção se multiplicou por seis e três vezes, respectivamente. No setor petrolífero, a descoberta de reservas nas águas do Golfo do México, e os investimentos da empresas chinesas foram fundamentais. $\mathrm{Na}$ área mineral, destaca-se a extração do níquel, sobretudo por meio de firmas canadenses (Pérez Villanueva, 2008: 51). Cumpre observar que esse era um antigo projeto das autoridades cubanas, e, durante a Guerra Fria, cogitou-se levá-lo adiante com capital japonês. Contudo, as tensões políticas daquele momento fizeram que os Estados Unidos vetassem a operação, pressionando seu principal aliado asiático.

As autoridades cubanas autorizaram a criação de empresas familiares, como os restaurantes caseiros que se tornaram conhecidos como "paladares", a partir de um estabelecimento semelhante montado pela protagonista da telenovela brasileira "Vale Tudo". Outros pequenos negócios foram estabelecidos na área turística, como serviços de táxi. Ao longo da década de 1990, a percentagem da população economicamente ativa empregada no setor privado alcançou $25 \%$.

As reformas econômicas falharam em uma área crucial: a agricultura. Medidas limitadas de privatização foram introduzidas para estimular os camponeses a trabalhar pequenas parcelas das fazendas coletivas estatais. $\mathrm{O}$ setor mais prejudicado foi o açucareiro, abandonado pelo Estado em virtude de sua pouca competitividade global no novo mundo do agronegócio. O governo fechou cerca de metade das usinas, o que resultou na perda de 100 mil empregos e na redução da produção para 1,2 milhões de toneladas em 2006 - contra mais de 8 milhões na década de 1980. Fidel Castro chegou a falar no fim da "era do açúcar", período histórico que associou à escravidão e ao analfabetismo (Pérez-López, 2008: 171).

A crise agrícola gerou problemas de segurança alimentar, e o governo cubano tem recorrido constantemente ao mercado internacional para se abastecer de comida. Estima-se que $60 \%$ das importações cubanas ao longo da década de 2000 sejam de alimentos (idem: 173). Ironicamente, um dos principais fornecedores de comida para Cuba são os Estados Unidos. Apesar do embargo, em 2000 o governo Clinton promulgou o Trade Sanctions Reform and Export Enhancements Act (TSRA), que permitia a venda de alimentos a Cuba, Irã e Sudão, desde que fossem atendidas certas condições, como situações de emergência humanitária, e o pagamento fosse feito à vista. ${ }^{1}$

Os negócios prosseguiram na administração norte-americana posterior. Patrick Symmes classifica o embargo de "rede cheia de buracos, uma fábula voluntária de exceções", pois "enquanto atacava Cuba verbalmente, Bush na verdade expandia o comércio, sob pressão dos congressistas dos estados rurais e do

1 Para o texto da lei, ver http://www.bis.doc.gov/licensing/tsranexpenhanceactfactsheet122101.html. Acesso em junho de 2009. 
agrobusiness" (Symmes, 2009: 211). As exportaçôes de alimentos para o mercado cubano se multiplicaram de US $\$ 4$ milhões (2001) para US $\$ 432$ milhōes (2007) (Pérez-López, 2008: 175-176).

Naturalmente, a expansão comercial se deu graças a interpretações bastante generosas do que constituiu uma "emergência humanitária", conforme prevista na TSRA. Apresar do pragmatismo econômico, os governos de Cuba e dos Estados Unidos evitam destacar a força do intercâmbio entre os dois países. Por razões de política doméstica, interessa a ambos reduzir a visibilidade dessas operações, de modo a não constrariar os grupos intransigentes às aproximações entre as duas nações.

\section{A nova agenda diplomática}

O pragmatismo comercial norte-americano, mesmo em meio à radicalização ideológica, deve ser interpretado no contexto da nova agenda diplomática de Cuba. O regime socialista logrou sobreviver ao fim do bloco soviético e superar o isolamento ao encontrar aliados econômicos e políticos na América Latina, América do Norte, Ásia e Europa. Nesse cenário, a reaproximação norte-americana também se explica pela constatação de perda de oportunidades de negócios e mesmo pelo desejo em influenciar as reformas cubanas.

Já foi argumentado que a política externa foi a iniciativa mais bem-sucedida da Revolução Cubana. ${ }^{2}$ Desde 1959, os cubanos enviaram expedições militares à África, médicos a diversos países em desenvolvimento, forneceram treinamento e armas a rebeldes em naçôes latino-americanas e estabeleceram influência internacional mais próxima a uma grande potência do que a uma pequena ilha. O fim da Guerra Fria mudou radicalmente o cenário de atuação da diplomacia cubana, mas o governo do país conseguiu estabelecer uma nova rede de aliados internacionais que evitou seu isolamento econômico e político. Para o historiador Rafael Rojas, "a política externa cubana passou de uma fase ofensiva, de promoção ideológica, política e militar do socialismo no mundo, para outra defensiva, na qual todos os recursos se destinam a recolher apoio internacional para o regime em seus conflitos com os Estados Unidos" (Rojas, 2006: 435).

Como abordado na seção anterior, as reformas econômicas resultaram no fortalecimento de vínculos com novos parceiros na área de comércio e investimentos, como China, União Européia (sobretudo Espanha) e Canadá. Os focos de interesse são os setores do turismo e dos recursos naturais - minérios e hidrocarbonetos. Estas relações ocasionalmente apresentam tensões políticas. Os europeus aplicaram sançôes contra Cuba no início da década de 2000, após uma onda repressiva de Havana que encarcerou quase cem dirigentes de associações de cidadãos com posições críticas ao governo.

2 Jorge Domínguez, professor da Universidade Harvard, em palestra na oficina "Cuba's International Relations Since 1959", no XXVIII congresso da Latin American Studies Association. Rio de Janeiro, 12 de junho de 2009. 
Dificuldades semelhantes ocorreram com o México. A política externa mexicana tradicionalmente deu grande importância a Cuba, com base no que Rafael Rojas chama de "amizade desleal": "Durante quase 40 anos, México e Cuba mantiveram um vínculo singular, em que dois regimes não-democráticos compartilhavam valores similares, provenientes de duas revoluções e dois nacionalismos, articulados frente à mesma potência hegemônica: os Estados Unidos. O pacto diplomático entre esses dois autoritarismos consistia em que o México se oporia ao isolamento internacional de Cuba, promovido pelos Estados Unidos, e em troca Cuba não estimularia movimentos da esquerda radical no México" (Rojas, 2004).

Esse acordo tácito foi rompido na década de 1990, quando sucessivos governos mexicanos empreenderam guinadas radicais de seu modelo de desenvolvimento e de inserção externa, abandonando o paradigma de substituição de importações e de defesa de bandeiras terceiro-mundistas pela adesão ao livre comércio do Nafta. Isso significou também o afastamento de Cuba e a adoção atitudes contrárias às violaçôes de direitos humanos por parte do governo cubano.

Contudo, a perda do tradicional aliado mexicano foi compensada pelo novo cenário político na América Latina. A partir de fins da década de 1990, governos de esquerda foram eleitos em diversos países da região. Os partidos e movimentos que integram essas coalizões tinham vínculos bastante fortes com Cuba, em muitos casos remontando às organizações de resistência armada contra as ditaduras militares dos anos 60 e 70. Em outras situações, como na Venezuela, o novo discurso em busca do "socialismo do século XXI" encarava a Revolução Cubana como referência ideológica fundamental, e preconizava a solidariedade ao país e apoio ao seu governo.

O novo quadro político regional é o mais favorável a Cuba desde a Revolução e resultou especialmente importante para as relaçôes com a Venezuela. Os dois países assinaram acordos em que trocavam petróleo barato por cooperação internacional na área de medicina e de segurança. Assim, o governo cubano assegurou fonte essencial de combustível e ainda ampliou seu prestígio externo, por meio da ida de milhares de médicos para a Missão Barrio Adentro, um programa social que cria centros de atendimentos de saúde em favelas e áreas pobres venezuelanas.

Em termos de comércio exterior, o quadro que se consolidou na década de 2000 indica que os principais destinos das exportações cubanas são os Países Baixos (importante entreposto portuário para o resto da União Européia), Canadá, Venezuela, China e Espanha. Tais naçóes correspondem a cerca de $75 \%$ das vendas cubanas ao exterior. As importações se concentram em Venezuela, China, Espanha, Alemanha e Estados Unidos, que formam cerca de 60\% do total (Pérez-López, 2008: 174). Os dados demonstram a importância da relação com a Venezuela de Chávez, mas também a relevância das novas parcerias com a União Européia, Canadá e China, além do crescimento dos Estados Unidos na pauta de importaçôes cubanas, em função da expansão do comércio agrícola entre os dois países. 
Comércio e investimentos evitaram o isolamento internacional de Cuba, mas a situação é ambígua no que toca aos fóruns regionais. A possibilidade do retorno cubano ao sistema interamericano tem sido levantada em diversas cúpulas multilaterais e culminou na decisão da Organização dos Estados Americanos (OEA) de anular a suspensão do país, vigente desde 1962. Contudo, o próprio governo cubano rejeitou a oferta, acusando a OEA de ser um "ministério das colônias ianques", ainda que reconhecendo que a resolução da organização marca "um dia histórico."

A ambiguidade cubana se explica em função do custo político em retornar à OEA. Reingressar na instituição significaria aderir a instrumentos como a Carta Democrática e a Corte Interamericana de Direitos Humanos, que permitem aos cidadãos apresentarem petições contra suas autoridades nacionais. Isso daria um novo e poderoso fórum para os dissidentes cubanos, em espaço político fora do controle do Estado socialista.

\section{Perspectivas para o diálogo entre Cuba e Estados Unidos}

Enquanto Cuba diversificava suas relações internacionais, os Estados Unidos promulgavam duas leis que dificultavam ainda mais a agenda bilateral com a ilha. A Torricelli (1992) e a Helms-Burton (1996) acrescentaram restrições ao embargo, em grande medida porque refletiam a convicção dos setores mais conservadores da comunidade cubano-americana de que o contexto da década de 1990 tornava possível destruir o regime socialista por meio do estrangulamento econômico.

Também conhecida como Lei da Democracia Cubana, a Lei Torricelli cria empecilhos para países e empresas que negociam com Cuba, como proibição de que navios que comerciem com a ilha aportem nos Estados Unidos em menos de 180 dias depois de passarem por portos cubanos. Estabelece ainda restriçóes para o envio de remessas de dólares a Cuba. ${ }^{4}$

A Helms-Burton aprofundou tais obstáculos e estabeleceu a possibilidade de sanções para empresas de fora dos Estados Unidos que tenham negócios em Cuba, em especial nas operaçóes que envolvam propriedade norte-americana confiscada após a Revolução. ${ }^{5}$ A lei foi muito contestada internacionalmente União Européia, Canadá e México promulgaram legislação para neutralizar seus efeitos - e se tornou um símbolo da intransigência dos Estados Unidos em dialogar com o governo de Fidel Castro.

3 “Cuba: un dia histórico". Em http://www.bbc.co.uk/mundo/america_latina/2009/06/090604_0422_ respuesta_cuba_oea_irm.shtml. Acesso em junho de 2009.

4 Texto completo disponível em http://www.state.gov/www/regions/wha/cuba/democ_act_1992.html. Acesso em junho de 2009.

5 Texto completo disponível em http://www.state.gov/www/regions/wha/cuba/helms.html. Acesso em junho de 2009. 
Contudo, é errôneo considerar a comunidade cubano-americana como monolítica, sempre em oposição a entendimentos com Cuba. São cerca de um milhão de pessoas, quase $90 \%$ do total de emigrados cubanos. Ao longo das décadas de 1990 e 2000 houve uma mudança geracional, com a morte ou saída da cena pública dos ativistas veteranos, que haviam vivido o período anterior à Revolução e passado pelos traumas da prisão, confisco da propriedade ou exílio (cerca de 25\% do total de cubano-americanos), como o célebre Jorge Mas Canosa, da Fundação Nacional Cubano-Americana. Seus filhos e netos (outros 25\%) começaram a despontar como líderes políticos e apresentaram posições mais moderadas, fruto de sua experiência pessoal bastante diversa.

Há também ampla parcela da comunidade emigrada para os Estados Unidos a partir do chamado "êxodo de Mariel", na década de 1980 (aproximadamente $50 \%$ ), motivada por razões econômicas, e não ideológicas, e que havia passado infância e adolescência sob a Revolução, com memórias mais ambivalentes com relação ao regime socialista (Eckstein, 2005: 207-208).

As novas geraçōes da comunidade cubano-americana divergem dos mais velhos em pontos cruciais da agenda política. Por exemplo, entre os jovens, $53 \%$ são favoráveis a terminar com o embargo econômico, contra apenas $30 \%$ entre a faixa idosa. Os mais novos também são bem mais simpáticos a facilitar as viagens para Cuba, e mais de $30 \%$ deles já estiveram na ilha, contra $18 \%$ dos velhos (Eckstein, 2005: 222). As atitudes privadas em mudança às vezes conflitam com os valores estabelecidos: "Mais de cem mil cubano-americanos regressavam à ilha todo ano, e não eram bobos de abrir o bico de um lado ou outro do estreito. Em Cuba, ficavam calados sobre política. E quando voltavam a Miami, ficavam calados sobre terem estado na ilha. Com o passar dos anos, alguns dos mais eloquentes defensores da proibição de viagens a Cuba foram pegos no Miami International [Airport] voltando de uma visita à família" (Symmes, 2009: 161).

A associação mais prestigiosa da geração em ascensão é o Conselho da Liberdade Cubana, cujos dirigentes foram recebidos inclusive pelo presidente George W. Bush. Eles declararam disposição para negociar com altos funcionários cubanos, contanto que não sejam os irmãos Castro.

Cumpre observar ainda o grande peso das remessas de dólares que os cubanoamericanos enviam para a ilha - cerca de US $\$ 1$ bilhão por ano, fundamentais para a problemática balança de pagamentos do país e para a manutenção de patamar mínimo de conforto para muitas pessoas. Como os cubanos observam de maneira bem-humorada, para lidar com as condições de vida na ilha, é importante ter FE - Família no Exterior.

Em síntese, o pragmatismo comercial do agronegócio e as mudanças na opinião política da nova geração de cubano-americanos constituem as bases para a proposta de um novo diálogo com Cuba lançada pelo presidente Barack Obama. Contudo, no que toca ao governo cubano, tais incentivos estão em grande medida ausentes. 
O colapso da União Soviética e as difíceis condições econômicas do "período especial" levaram o regime socialista cubano a redefinir muitos elementos de seu discurso ideológico. A chamada "batalha das idéias" tem sido travada com recursos que devem mais à tradição nacionalista cubana do que aos cânones do marxismo-leninismo (Domingues, 2008; Rojas, 2006: 428-447). Um dos pilares dessa estratégia é que o "o principal argumento de legitimidade que restou ao governo de Castro e uma das maiores razões para a continuidade de sua existência é a credibilidade de incorporar a oposição nacionalista à agressão dos Estados Unidos" (Portes, 2005: 190).

A saída de Fidel Castro do poder e sua substituição pelo irmão caçula, Raúl, não alterou a situação. Desde a Revolução, o mais jovem dos Castro representa as posiçôes mais rígidas do ponto de vista ideológico. Ministro da Defesa desde 1959, Raúl se notabilizou com administrador hábil, que tem utilizado de maneira crescente as Forças Armadas para desempenhar atividades econômicas, gerenciando empresas e projetos de desenvolvimento. Durante o período especial ele assumiu o controle da burocracia rival do Ministério do Interior, que contava inclusive com unidades de combate e com serviços de segurança que incomodavam os militares. $\mathrm{O}$ processo não foi isento de conflitos e culminou no fuzilamento de um dos melhores amigos de Raúl - o general Arnaldo Ochoa, herói das guerras africanas. Oficialmente condenado por narcotráfico, é possível que sua execução tenha sido causada por comentários críticos a Fidel, em momento delicado para o regime cubano, que temia a possibilidade uma insurreição entre as Forças Armadas (Latell, 2005: 207-223).

Em cinquenta anos à frente dos militares, Raúl logrou evitar qualquer tentativa de golpe, rebelião ou atentado contra o governo. Ele também cuidou da cooperação externa, mesmo com os adversários. Há uma discreta, mas eficiente, colaboração entre os militares de Cuba e Estados Unidos, principalmente no que diz respeito ao combate ao tráfico de drogas no Caribe. Os dois países também trabalharam em conjunto em questóes de segurança internacional. Por exemplo, não houve oposição cubana à instalação em Guantánamo dos suspeitos de terrorismo, e as autoridades chegaram a afirmar que eventuais fugitivos seriam devolvidos à base. Tampouco foram feitas críticas com relação à missão de estabilização da ONU no Haiti - Havana entende que uma crise no país teria impactos negativos para toda a região, em função de migrações de refugiados e instabilidade política (idem: 245-246).

Um ano após tomar posse na presidência de Cuba, Raúl Castro realizou uma ampla reforma ministerial, afastando 11 colaboradores do irmão, inclusive estrelas da política cubana como o chanceler Felipe Pérez-Roque e o vice-presidente Carlos Lage. Ambos haviam pertencido ao chamado Grupo de Apoio, uma força-tarefa formada por jovens tecnocratas que assessorava Fidel com relação aos mais diversos temas, em particular a implementação das reformas econômicas.

Com quase 80 anos, Raúl Castro não demonstra entusiasmo por reviravoltas políticas. Realizou pequenas reformas econômicas, no sentido de facilitar a 
importação de bens de consumo (eletrodomésticos e celulares) e expandir a privatização agrícola iniciada por seu irmão. Contudo, seus principais colaboradores são dirigentes conservadores das Forças Armadas e do Partido Comunista. A corrente reformista, favorável ao aprofundamento das relações com a América Latina, foi enfraquecida com o afastamento de Pérez-Roque e Lages.

Em resumo: "Não há, em conseqüência, uma agenda de mudanças democráticas sob nenhuma perspectiva, seja liberal ou socialista. E tampouco creio que exista entre os cubanos uma tendência dominante a pressionar - ao menos no momento - por estas transformações políticas. Nesse sentido, a elite pode, também sob este aspecto, trabalhar no curto prazo sem pressões significativas" (Dilla Alfonso, 2005: 43).

Essa é a conjuntura política que explica a reação fria do governo cubano à proposta de retomada do diálogo com os Estados Unidos. ${ }^{6} \mathrm{Na}$ ausência de crises dramáticas na economia ou na oposição interna, Havana tem mais a perder do que em ganhar discutindo com Washington questóes controversas como a suspensão do embargo econômico ou a situação dos prisioneiros políticos. Contudo, há espaço para avanços significativos em temas importantes, como o comércio de alimentos (sobretudo neste cenário de alta do preço das commodities agrícolas, piorando o balanço de pagamentos cubano), facilitação das relações entre famílias divididas entre os dois países e mesmo uma discreta, mas efetiva, cooperação militar.

Expectativas moderadas e uma clara noção dos limites do possível podem levar a melhoria expressiva das relações entre Estados Unidos e Cuba, abrindo possibilidades positivas para o futuro imprevisível após a morte dos irmãos Castro. A ausência de uma figura pública com legitimidade comparável a dos líderes revolucionários pode criar um perigoso vácuo político, com o risco de disputas violentas pelo poder. Nesse contexto, faz sentido que Washington aposte na construção de vínculos de confiança com altos funcionários do governo cubano, nas esferas diplomática, militar e econômica, que seriam de grande valia num cenário turbulento como esse.

\section{Conclusões}

Os países do bloco socialista passaram por trajetórias muito diversas no pós-Guerra Fria, indo do colapso da URSS, à integração da Europa Oriental nas instituiçôes ocidentais (União Européia e OTAN) ao crescimento econômico acelerado da China e do Vietnã, passando pelo isolamento e pela militarização da Coréia do Norte. Cuba ocupa uma posição intermediária entre essas histórias de sucesso e fracasso. Seu regime político conseguiu sobreviver à queda de seu patrocinador internacional, e reinventar sua economia e sua inserção externa.

6 Ver, por exemplo, a análise da historiadora norte-americana Julia Sweig, após entrevistar líderes cubanos: www.cfr.org/publication/18715/wariness_in_cuba_toward_the_obama_administration.html?breadcrumb =\%2Fregion\%2F213\%2Fcuba. Acesso em março de 2009. 
Porém, os custos de tais mudanças foram altos, com impactos negativos da qualidade de vida da população.

As reformas econômicas tornaram o país menos dependente do açúcar e do tabaco, com a prosperidade do setor de mineração e do turismo, ainda que este traga diversas conseqüências sociais adversas. A agenda externa se diversificou, com o estabelecimento de parcerias importantes com Venezuela, China, União Européia e Canadá. O grande fracasso das medidas renovadoras tem sido a agricultura, que continua com baixa produtividade e com efeitos negativos na macroeconomia, como no balanço de pagamentos.

A ausência de abertura política é frustrante para diversos segmentos da população cubana, mas não significou o surgimento de pressões intensas pela liberalização do regime. Não houve choques comparáveis às manifestações massivas que derrubaram os regimes da Europa Oriental, nem choques violentos como aqueles que aconteceram na China. Internacionalmente, houve conflitos ocasionais com a União Européia e o México, mas nada que atrapalhasse as negociações com a maioria dos países da América Latina.

O diálogo entre Estados Unidos e Cuba tem oscilado entre o endurecimento e pragmatismo. No primeiro campo, destacam-se as leis restritivas da década de 1990, como a Torricelli e a Helms-Burton. No segundo, a expansão do comércio, impulsionada pelo lobby dos exportadores agrícolas norte-americanos. As transformações na comunidade cubano-americana, com a ascensão de uma geração mais jovem e aberta a entendimentos com o governo cubano, é um importante fator de mudança.

Contudo, não se deve esperar muito dessas negociações. As condições não estão maduras para o consenso em torno dos temas mais polêmicos, quando mais não seja porque o governo cubano depende, para sua legitimidade, de ser considerado o grande defensor do país contra as agressões dos Estados Unidos. Resta, porém, amplo campo para avanços significativos em assuntos de menor relevância política, mas de importância humanitária, como a questão das famílias divididas entre os dois países.

\section{Referências bibliográficas}

DILLA ALFONSO, Haroldo. "La dirección y los límites de los cambios". Publicado na Revista Nueva Sociedad - Edição n. 216. 2008. Publicado em: [http://www.nuso.org/upload/ articulos/3532_1.pdf]. Disponibilidade: 26/09/2009.

DOMINGUES, José Maurício. “A Revolução Cubana entre o passado e o futuro”. Publicado no Observatório Político Sul-Americano do Iuperj. Análise de Conjuntura n.3. 2008. Publicado em: [http://observatorio.iuperj.br/pdfs/44_analises_AC_n_3_mar_2008.pdf]. Disponibilidade: 26/09/2009.

ECKSTEIN, Susan. "The Transformation of the Diaspora and the Transformation of Cuba”. In: J. Tulchin et alli. Changes in Cuban Society since the Nineties. Washington: Woodrow Wilson Center for International Scholars, 2005, p. 207-229. 
LATELL, Brian. After Fidel: Raul Castro and the future of Cuba's revolution. Nova York: Palgrave Macmillan, 2005.

PÉREZ-LÓPEZ, Jorge. “Tiempos de Cambio: tendencias del comercio exterior cubano." Publicada na Revista Nueva Sociedad - Edição n. 216. 2008. Publicado em: [http://www. nuso.org/upload/articulos/3541_1.pdf]. Disponibilidade: 26/09/2009.

PÉREZ-VILLANUEVA, Omar E (2008). "La Economía en Cuba: un balance necesario y algunas propuestas de cambio”. Publicada na Revista Nueva Sociedad - Edição n. 216. 2008. Disponível em [http://www.nuso.org/upload/articulos/3533_1.pdf]. Disponibilidade: 26/09/2009.

PORTES, Alejandro. "The Cuban-American Political Machine: reflections on its origins and perpetuation”. In: J. Tulchin et alli. Changes in Cuban Society since the Nineties. Washington: Woodrow Wilson Center for International Scholars, 2005, p. 187-206.

ROJAS, Rafael. "Mexico y Cuba: amigos desleales”. Foreign Affairs en Español. N.3, julhosetembro, 2004, p. 72-82.

(2006). Tumbas sin Sosiego: Revolución, disidencia y exilio del intelectual cubano. Barcelona: Anagrama, 2006.

SYMMES, Patrick. Os Meninos do Dolores: os colegas de classe de Fidel, da Revolução ao exílio. Rio de Janeiro: Record, 2009.

Recebido em 29 de setembro de 2009

Aprovado em 14 de janeiro de 2010

\section{Resumo}

Cuba passou por muitas transformações após a Guerra Fria. A economia está mais diversificada e o país logrou escapar do isolamento internacional, estabelecendo parcerias com China, União Européia e América Latina. Além disso, a transformação na comunidade cubano-americana coloca em posições de influência ativistas mais jovens, com maior disposição para o diálogo com os Estados Unidos, inclusive em temas comerciais. Contudo, é difícil que as negociações avancem em pontos controversos, pela relutância de Havana em liberalizar o regime político.

\section{Abstract}

Cuba has undergone several transformations after the Cold War. The economy has become more diversified and the country has been able to overcome international isolation, and in so doing establish partnerships with China, the European Union and Latin America. In addition, the changes in the Cuban-American community have put younger activists who are more willing to enter into dialogue with the United States, on such matters for example as foreign trade. However, it is difficult for the negotiations to solve more controversial points because of the continued reluctance of Havana to liberalize the political regime.

Palavras-chave: Cuba; comércio exterior; política externa.

Key-words: Cuba; foreign trade; foreign policy. 